\title{
Correction: SARS-CoV-2 vaccination intentions among mothers of children aged 9 to 12 years: a survey of the All Our Families cohort
}

A clarification is required for an article published May 21, $2021 .{ }^{1}$ In the Results section of the abstract, the sentence "Lower education, lower income and incomplete vaccination history were inversely associated with intention to vaccinate." has been revised to "Participants with lower education, lower income and incomplete vaccination history were less likely to intend to vaccinate their children."

The article has been updated at cmajopen.ca.

\section{Reference}

1. Hetherington E, Edwards SA, MacDonald SE, et al. SARS-CoV-2 vaccination intentions among mothers of children aged 9 to 12 years: a survey of the All Our Families cohort. CMA7 Open 2021;9:E548-55.

CMAJ Open 2021. DOI:10.9778/cmajo.20210169 